\title{
Vinculin: Its Possible Use as a Marker of Normal Collecting Ducts and Renal Neoplasms with Collecting Duct System Phenotype
}

\author{
Naoto Kuroda, M.D., Keishi Naruse, M.D., Eriko Miyazaki, C.T., Yoshihiro Hayashi, R.A., \\ Chiaki Yoshikawa, R.A., Shingo Ashida, M.D., Toshiaki Moriki, M.D., Yoshikazu Yamasaki, M.D., \\ Satoshi Numoto, M.D., Yukio Yamamoto, M.D., Ichiro Yamasaki, M.D., Makoto Hiroi, M.D., \\ Taro Shuin, M.D., Hideaki Enzan, M.D. \\ From First Department of Pathology (NK, KN, EM, YH, MH, HE), Department of Urology (CY, SA, IY, TS) \\ and Department of Central Laboratory (TY), Kochi Medical School, and Department of Clinical \\ Laboratory, Kochi Red Cross Hospital (YoY), Department of Diagnostic Pathology, Kochi Municipal \\ Hospital (SN), and Department of Urology, Chikamori Hospital (YuY), Kochi, Japan
}

\begin{abstract}
Vinculin is a cytoskeletal protein associated with membrane actin-filament-attachment sites of cellcell and cell-matrix adherens-type junctions. In this article, we examine the expression of vinculin to elucidate its role in human renal neoplasms. We reviewed surgically resected specimens and selected available tissue from 79 renal tumors in 78 patients. There were 55 men and 23 women. Their mean age was 61 years and the mean size of the renal tumors was $6.1 \mathrm{~cm}$. All renal tumors were examined by immunohistochemistry using a monoclonal antibody against vinculin. Overall, $17(21.5 \%)$ renal tumor samples reacted with vinculin. The positive ratio in various types of renal tumors was as follows: conventional-type (clear cell), 0/54; papillary-type, 5/12; chromophobe-type, 5/5; sarcomatoid-type, 3/4; collecting duct carcinoma, $3 / 3$; and oncocytoma, $1 / 1$. The positive rate of conventional-type renal cell carcinomas (RCCs) is significantly different from that of other renal tumors $(P<.01)$. Normal kidney, conventional, and papillary-type RCCs exhibited positive signals in Western blot analysis. These results suggest that vinculin may serve as a useful marker of renal neoplasms with collecting duct system phenotype such as chromophobe-type RCC.
\end{abstract}

KEY WORDS: Renal cell carcinoma (RCC), Vinculin. Mod Pathol 2000;13(10):1109-1114

Copyright (C) 2000 by The United States and Canadian Academy of Pathology, Inc.

VOL. 13, NO. 10, P. 1109, 2000 Printed in the U.S.A.

Date of acceptance: April 20, 2000.

Supported in part by a Grant for Encouragement of Young Scientists (11770092) from the Ministry of Education, Science and Culture, Japan. Address reprint requests to: Naoto Kuroda, MD, Department of Pathology, Kochi Medical School of Medicine, Kohasu, Oko-cho, Nankoku City, Kochi 783-8505, Japan; fax: 81-88-880-2332.
Vinculin is a 117-130 kDa cytoskeletal protein containing 1066 amino acids (1-3). Its gene is encoded on human chromosome 10q11.2-qter (4). Recently, the complete sequences of human as well as chick and nematode proteins have been published (4). Ultrastructurally, vinculin appears to have a globular head and an extended tail (3). The head contains the $N$-terminus of the protein, an $\alpha$-actinin binding site (residues 1-107), a talin-binding site (residues 1-258), and three 112-residue repeats of unknown function (5-7). The head can be liberated as a 90$\mathrm{kDa}$ fragment from the tail $(30 \mathrm{kDa})$ by V8-protease cleavage within a proline-rich region (3). The 30 $\mathrm{kDa}$ tail contains a paxillin-binding site (residue 978-1000) and an F-actin binding site (residue 8931016) $(8,9)$. It is well known that vinculin is widely distributed in human tissue and is expressed where smooth muscle actin and fibroblasts attach to the extracellular matrix $(2,10)$. Rahilly et al. (11) reported that vinculin was distributed in renal tubular epithelium. However, little is known about the distribution of vinculin in various subtypes of renal tumors. Here, we immunohistochemically examined the expression of vinculin protein in normal human fetal and adult kidneys and resected renal tumors to elucidate the role of vinculin in human renal neoplasm.

\section{MATERIALS AND METHODS}

\section{Renal Tissues}

Between 1983 and 1998, 96 nephrectomies were performed for renal tumors at Kochi Medical School. We reviewed the surgically resected specimens and selected formalin-fixed, paraffinembedded tissue sections of 79 renal tumors from 78 patients by excluding cases of poorly preserved 
renal tumor, angiomyolipoma, juxtaglomerular cell tumor, and nephroblastoma. There were 55 men and 23 women. The mean age of the patients was 61 years, with a range of 28 to 83 years. The mean size of renal tumors was $6.1 \mathrm{~cm}$, with a range of 1.9 to 21 $\mathrm{cm}$. Hematoxylin-eosin staining preparations were reviewed by NK and TM, and histologically subdivided into six categories according to the current classification (Workgroup No.1) (12): conventionaltype (clear cell) RCC (54 cases), papillary-type RCC (12 cases), chromophobe-type RCC (five cases), sarcomatoid-type RCC (four cases), collecting duct carcinoma (three cases), and oncocytoma (one case). Five cases of chromophobe-type RCC included two with a typical variant and three with an eosinophilic variant. Tumors that were located in the medulla and had a predominantly tubular configuration, a desmoplastic stromal reaction, and atypical hyperplasia of the collecting duct epithelium adjacent to the neoplasia were taken as collecting duct carcinoma. The diagnosis of three collecting duct carcinomas was confirmed by the presence of immunoreactivity for both UEA-1 and high molecular weight cytokeratin $(34 \beta E 12)$. Four tumors with sarcomatoid-type RCC originated in three conventional-type RCCs and one collecting duct carcinoma. One tumor with oncocytoma consisted of cells arranged in alveolar nests and was focally separated by hyalinized fibrous tissues. Three samples of normal renal tissue adjacent to the main tumor tissues were prepared as normal controls.

\section{Immunohistochemistry}

Immunohistochemical stains were performed on $3 \mu \mathrm{m}$-thick formalin-fixed and paraffin-embedded tissues using Histofine simple stain PO (multi) kit (Nichirei, Tokyo, Japan). Mouse monoclonal vinculin antibody (Clone: V284) is now available from Novo Castra. The sections were mounted on silanecoated slides, incubated in $0.1 \mathrm{M}$ citric acid buffer (pH6.0), and microwaved (5 min, three times). After the sections lay at room temperature, they were deparaffinized in xylene (5 min, four times) and dehydrated in graded ethanol. After they were washed in water, the sections were incubated with $3 \%$ hydrogen peroxide/PBS for $15 \mathrm{~min}$, again washed in water for $5 \mathrm{~min}$, and finally treated with monoclonal anti-vinculin antibodies (diluted $1: 100$ ), for $1 \mathrm{~h}$ at room temperature. Each incubation was followed by a PBS rinse for $5 \mathrm{~min}$, three times. Subsequently, the sections were incubated with anti-mouse IgG and anti-rabbit IgG conjugated with peroxidase for $30 \mathrm{~min}$ at room temperature. After they were washed with Tris buffer for 5 min, 3,3'-diaminobenzidine (Sigma Chemical, St. Louis, MO) was applied to confirm the presence of the immune complex. The sections were counterstained with hematoxylin and mounted.

\section{Statistical Analysis}

For comparisons of immunostaining positivity between various subtypes of renal tumors contained groups with small numbers of tumors, we used the $\chi^{2}$ test or Fisher's exact probability test for the statistical analysis of this study.

\section{Western Blotting}

Fifteen micrograms of protein samples of normal kidney tissue, conventional-type RCCs, and papillarytype RCCs were subjected to $10 \%$ SDS-PAGE, then electrotransferred onto nitrocellulose filters for Western blot analysis. The monoclonal antibody against vinculin (V284) was used. The immunocomplex was detected using 3,3'-diaminobenzidine (Sigma Chemical). We used normal kidney tissue as a positive control and Kaleidoscope Prestained Standard (BIO-RAD, Tokyo, Japan) as a hallmark of the molecular weight.

\section{RESULTS}

Immunohistochemical Localization of Vinculin in Normal Human Tissue

We noted intense staining for vinculin in the ureteric buds, collecting ducts, parts of Bowman's capsule, parts of undifferentiated mesenchymal cells, and the vascular wall in fetal kidneys (Fig. 1A). In adult human kidneys, vinculin was intensely expressed in the cells of distal tubules and collecting ducts from normal renal tissues sampled at a distance from the tumors and the vascular wall, but they did not react with the cells of proximal tubules and glomeruli except for capillary walls (Fig. 1B).

\section{Immunohistochemical Vinculin Expression in Human Renal Tumors}

The immunohistochemical results of vinculin protein expression in all the examined renal tumors are shown in Table 1. Overall, 17 of 79 renal tumor samples $(21.5 \%)$ stained for vinculin protein. The staining pattern of vinculin protein was homogenous in six of the positive specimens and heterogenous in the other 11 cases. Although vinculin was present in the vascular components of conventional-type (clear cel) RCC, no positive immunostaining for vinculin was detected in tumor cells of this RCC, and a relation to specific subtypes was evident. The vinculin positive ratio was as follows: papillary-type, 5/12; chromophobe-type, 5/5; sarcomatoid-type, 3/4; collecting duct carcinoma, $3 / 3$; and oncocytoma, $1 / 1$. The staining pattern of vinculin is shown in Figure 2, A-G. Vinculin was observed in the cytoplasm of neoplastic cells in 

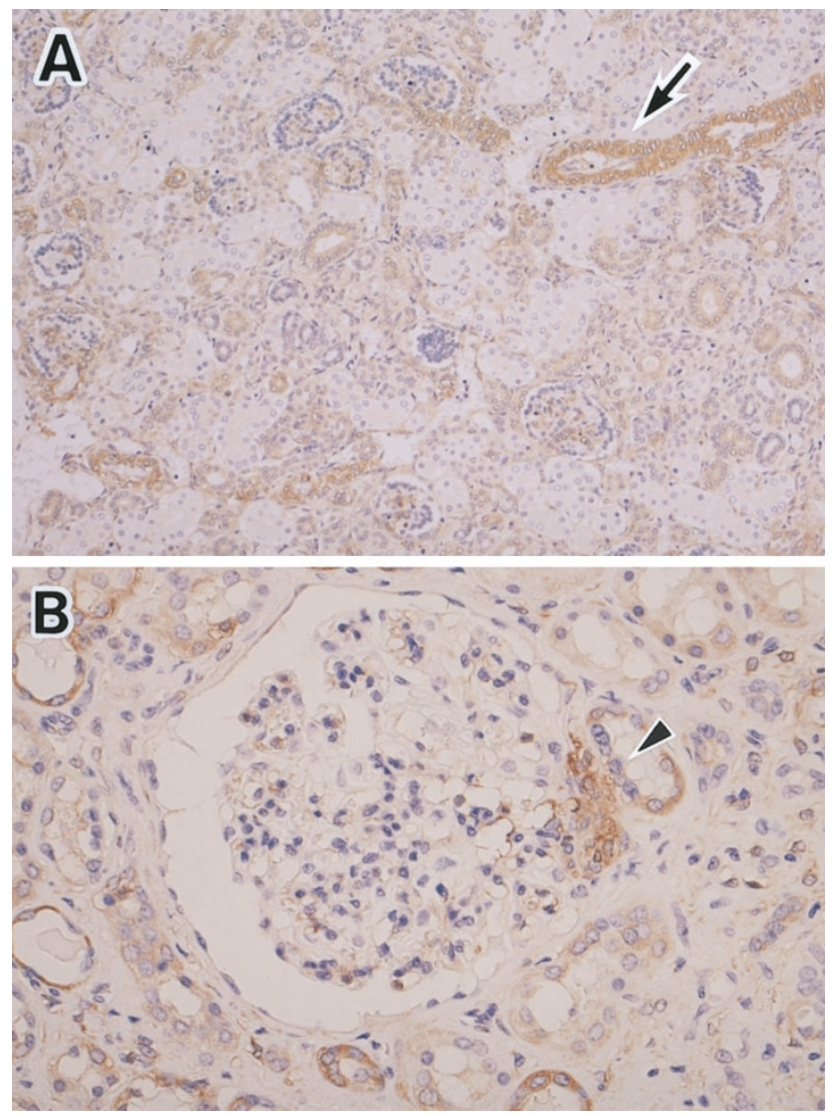

FIGURE 1. Expression of vinculin protein in human fetal and adult normal kidney. A, fetal kidney. Vinculin antibody intensely stains distal tubules, collecting ducts (arrow), parts of Bowman's capsule, parts of undifferentiated mesenchymal cells, and vascular wall in fetal kidney. B, adult normal kidney. Vinculin is intensely expressed chiefly in the cells of distal tubules including juxtaglomerular apparatus (arrowhead), collecting ducts, and vascular wall.

TABLE 1. Expression of Vinculin in Various Types of Renal Tumors

\begin{tabular}{lccc}
\hline \multicolumn{1}{c}{ Subtype } & Number & Positive & Ratio \\
\hline Conventional & 54 & 0 & $0 / 54$ \\
Papillary & 12 & 5 & $5 / 12$ \\
Chromophobe & 5 & 5 & $5 / 5$ \\
Collecting duct & 3 & 3 & $3 / 3$ \\
Sarcomatoid & 4 & 3 & $3 / 4$ \\
Oncocytoma & 1 & 1 & $1 / 1$ \\
Total & 79 & 17 & $17 / 79$ \\
\hline
\end{tabular}

papillary-type, sarcomatoid-type RCCs, collecting duct carcinoma, and oncocytoma. However, it was also distributed on the plasma membrane as well as the cytoplasm in chromophobe-type RCC. Moreover, the intensity of cytoplasmic staining of tumor cells with an eosinophilic variant was evidently stronger than that of tumor cells with a typical variant in chromophobe-type RCCs (Fig. 2, C-D). The positive rate of conventional-type (clear cell) RCC was significantly different from that of other renal tumors $(P<$ .01). There was also a significant difference between each positive rate of conventional-type (clear cell) RCC and that of chromophobe-type RCC $(P<.01)$.

\section{Western Blotting}

Signals in accordance with the molecular weight of vinculin were detected not only in normal kidneys, but also in conventional-type (clear cell) RCCs. Papillary-type RCCs showed the strongest signal for vinculin (Fig. 3).

\section{DISCUSSION}

Histological classification of renal tumors has been based on the traditional speculation regarding their histogenesis and differentiation. The World Health Organization (WHO) and the Armed Forces Institute of Pathology (AFIP) assumed the proximal tubular system as the origin for common renal tumors and described cellular phenotype and growth pattern $(13,14)$. Thoenes et al. (15) extrapolated the presumed cellular origin, comparing the tumor cells with their counterparts in the mature renal tubular system, and classified renal tumors on the basis of cytoplasmic staining features.

Molecular cytogenetics using chromosomal analysis has come to play an important role in the classification of renal tumors (16-18). According to the evidence of cytogenetical studies, the Heidelberg classification was proposed in 1997 and the WHO classification has also revised it in 1998 (19, 20).

As it is still possible to classify renal tumors without cytogenetic information, we employed the current classification in this article (12). In this study, no cases of conventional-type (clear cell) RCC showed a positive reaction for vinculin. In other words, renal tumors immunoreactive for vinculin are essentially not conventional-type (clear cell) RCCs. As it is well known that conventional-type (clear cell) RCCs show a proximal tubule phenotype, this result is compatible with that of a normal kidney. All cases with positivity for vinculin displayed other histologic subtypes of RCCs. The positivity of nonconventional renal tumors was significantly different from that of conventional-type (clear cell) RCC. There was also a significant difference between each positivity of conventional-type (clear cell) RCC and that of chromophobe-type RCC.

Chromophobe-type RCC is divided into three categories (21-23). In a typical variant, tumor cells are present with light, but not clear, cytoplasm displaying a fine reticular pattern. In an eosinophilic variant, the cytoplasm is finely granular, sometimes with a hint of transparency, yet elsewhere it is almost purely eosinophilic. Ultrastructurally, a typical variant contains numerous microvesicles and an eosinophilic variant contains more mitochondria than the former (21). In an oncocytic variant, tumor cells exhibit markedly eosinophilic or gran- 

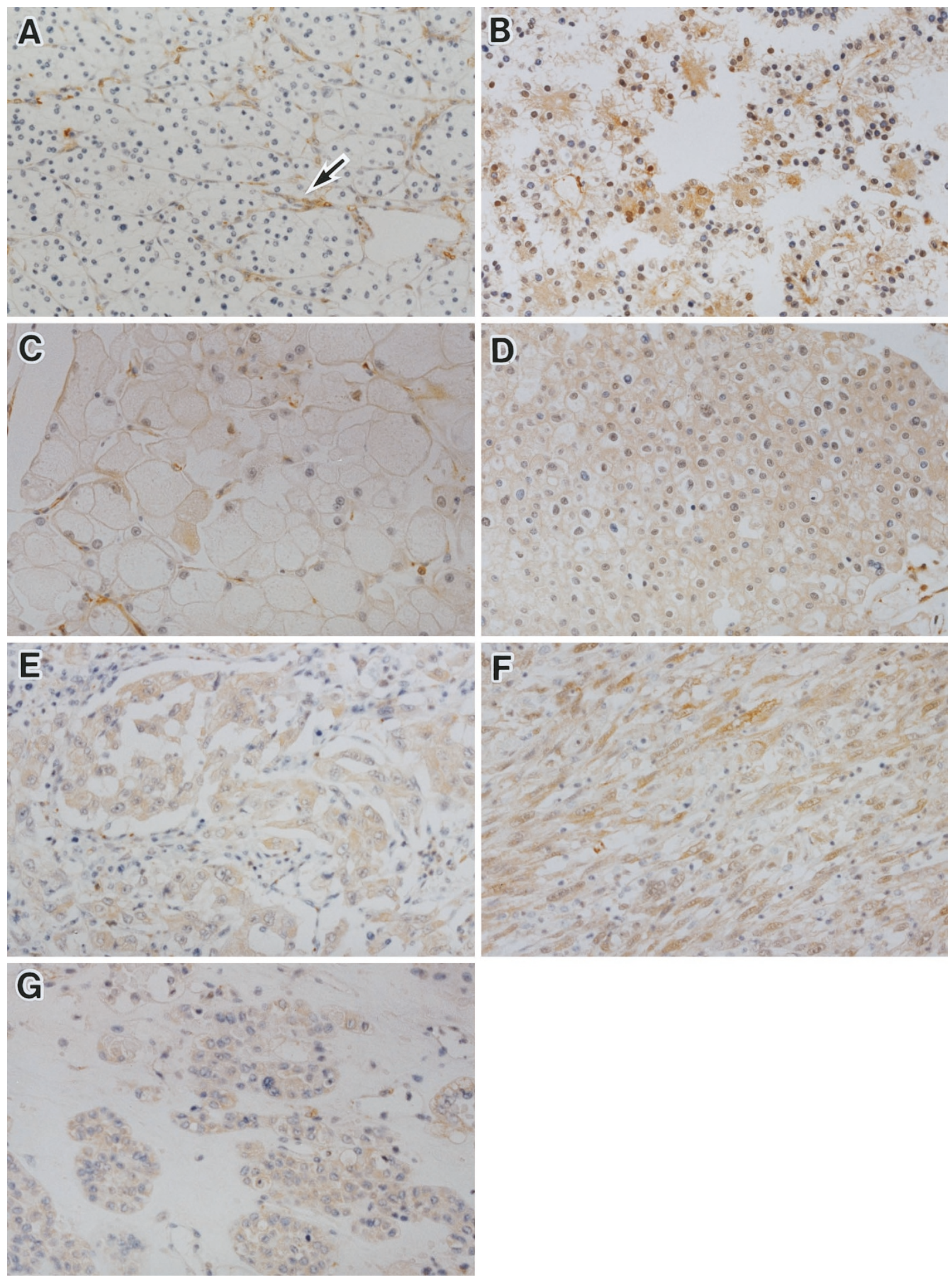

FIGURE 2. Expression of vinculin protein in various subtypes of renal tumor. A, conventional-type (clear cell) RCC. Although vinculin was present in the stromal vessel (arrow), it was negative in the neoplastic cells. B, papillary-type RCC. Tumor cytoplasms focally reacted with vinculin. C, typical variant of chromophobe-type RCC. Vinculin was chiefly observed on the plasma membrane and weakly expressed also in the cytoplasm. D, eosinophilic variant of chromophobe-type RCC. An intense positivity in the cytoplasm as well as on the plasma membrane was noted. E, collecting duct carcinoma. Tumor cytoplasms were focally positive for vinculin. F, sarcomatoid-type RCC, derived from conventional-type (clear cell) RCC. Spindle neoplastic cells were diffusely positive for vinculin. G, oncocytoma. Tumor cells exhibt a positive staining in the cytoplasm. 


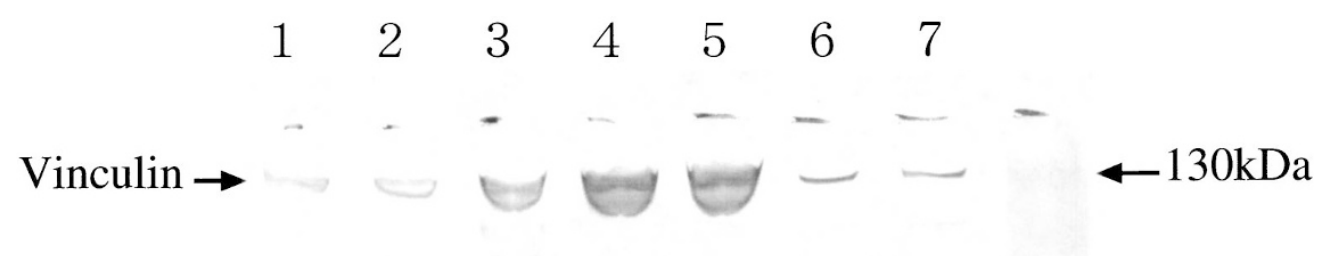

FIGURE 3. Western blotting of vinculin. Although all samples show a signal for vinculin at about $130 \mathrm{kDa}$, strongest signals were detected in papillary-type RCC. Lane 1, 2, 3, conventional-type (clear cell) RCC; Lane 4, 5, papillary-type RCC; Lane 6, 7, adult normal kidney.

ular cytoplasm, which are ultrastructurally devoid of cytoplasmic microvesicles and are filled with mitochondria (22). It is necessary to differentiate the typical, eosinophilic, and oncocytic variants from clear/granular (conventional)-type RCC and oncocytoma, respectively. As these tumors exhibit a different prognosis, the differential diagnosis is very important. Although it is generally easy to differentiate these tumors by routine macroscopic and microscopic findings, we often encounter some difficult cases. From the results of the present study, the immunohistochemical analysis of vinculin may be very useful in distinguishing typical and eosinophilic variants of chromophobe-type RCC from clear/granular (conventional)-type RCC. Moreover, the intensity of vinculin cytoplasmic staining of tumor cells with an eosinophilic variant was evidently stronger than that of tumor cells with a typical variant in the present study. In papillary-type RCC and collecting duct carcinoma, however, the staining pattern for vinculin did not show a significant difference between clear and granular cytoplasms.

On Western blot analysis, conventional-type (clear cell) RCCs as well as normal kidney tissues showed a signal in accordance with the molecular weight of vinculin. Because no cases of conventional-type (clear cell) RCC immunohistochemically expressed vinculin in tumor cells, this result seems contradictory. However, we suggest that the signal of vinculin in conventional-type (clear cell) RCCs on Western blot analysis may accord with its expression in the stromal vessels. Contrasted with conventional-type (clear cell) RCCs and normal renal tissues, papillary-type RCCs showed high intensity signal, probably owing to vinculin expression in neoplastic cells.

Recent reports demonstrate that sarcomatoidtype RCCs were derived from various types of renal tumors, such as conventional-, papillary-, and chromophobe-type RCCs and collecting duct carcinoma (22-26). In the present study, four tumors with sarcomatoid-type RCC originated in three conventional-type (clear cell) RCCs and one collecting duct carcinoma. Interestingly, the immunohistochemistry of vinculin in sarcomatoid-type RCCs derived from conventional-type (clear cell) RCCs showed a positive reaction in sarcomatous areas of two tumors out of three, but one was completely negative. In other words, conventional-type (clear cell) RCCs express vinculin after a sarcomatoid transformation. This result may reflect a transformation into the mesenchymal phenotype of epithelial neoplastic cells as suggested by the presence of vinculin in the stromal cells or represent a possible involvement of vinculin in the process of sarcomatoid transformation in conventional-type (clear cell) RCCs.

There have been several studies of other markers for distinguishing subtypes of RCC in the last several years $(27-30)$. Tickoo et al. $(27,28)$ have tried to differentiate renal tumors by staining pattern with colloidal iron staining or antimitochondrial antibody 113-1. However, it seems difficult for general pathologists to accurately evaluate their staining pattern. This author (29) and Taki et al. (30) have tried to differentiate chromophobe-type RCC or oncocytoma from other conventional-type (clear cell) RCC with SHP2 or E- and $N$-cadherins, respectively. Similar to these findings, it seems to us that the evaluation of vinculin expression is simpler and more useful compared with that of other antibodies.

On the other hand, it is often difficult to distinguish collecting duct carcinoma from papillarytype RCC occurring in the medulla. Since $41.7 \%$ of papillary-type RCC showed positive for vinculin, this antibody is not helpful in the differential diagnosis among these tumors.

In conclusion, renal tumors including chromophobetype RCC, collecting duct carcinoma, and oncocytoma, which are considered to have the phenotype of collecting ducts, show the high positive rates for vinculin. In contrast to these tumors, conventional-type (clear cell) RCC do not express vinculin as long as they do not show a sarcomatoid transformation. This result suggests that vinculin may be a useful marker in distinguishing renal neoplasms with collecting duct system phenotype, such as chromophobe-type RCC, and conventional-type (clear cell) RCC. 
Acknowledgments: We are grateful to Assistant Professor Ralph Schultejohann, Department of English, Kochi Medical School, for English correction of our manuscript and to Mr. Tadatoshi Tokaji, Ms. Hisayo Yamasaki, Ms. Miko Mitani, Mrs. Naoyo Nakamura, First Department of Pathology, Kochi Medical School for their excellent technical assistance. We are much obliged to Professor Yuji Ohtsuki, Second Department of Pathology, Kochi Medical School, for his encouragement and Mr. Katsumi Iwata, Laboratory of Pathology, Kochi Municipal Central Hospital, for his offer for RCC cases.

\section{REFERENCES}

1. Geiger B. A $130 \mathrm{~K}$ protein from chicken gizzard: its localization at the termini of microfilament bundles in cultured chicken cells. Cell 1979;18:193-205.

2. Burridge K, Feramisco JR. Microinjection and localization of a $130 \mathrm{~K}$ protein in living fibroblasts: a relationship to actin and fibronectin. Cell 1980;19:587-95.

3. Hemmings S, Barry ST, Critchley DR. Cell-matrix adhesion: structure and regulation. Biochem Soc Trans 1995;23:61926.

4. Weller PA, Ogryzko EP, Corben EB, Zhidkova NI, Patel B, Proce GJ, et al. Complete sequence of human vinculin and assignment of the gene to chromosome 10. Proc Natl Acad Sci U S A 1990;87:5667-71.

5. Kroemker M, Rudiger AH, Jockusch BM, Rudiger M. Intramolecular interactions in vinculin control $\alpha$-actinin binding to the vinculin head. FEBS Lett 1994;355:259-62.

6. Johnson RP, Craig SW. An intramolecular association between the head and tail domains of vinculin modulates talin binding. J Biol Chem 1994;269:12611-9.

7. Gilmore AP, Jackson P, Waites GT, Critchley DR. Further characterization of the talin-binding site in the cytoskeletal protein vinculin. J Cell Sci 1992;103:719-31.

8. Wood CK, Turner CE, Jackson P, Critchley DR. Characterisation of the paxillin-binding site and the C-terminal focal adhesion targeting sequence in vinculin. J Cell Sci 1994;107: 709-17.

9. Johnson RP, Craig SW. F-actin binding site masked by the intramolecular association of vinculin head and tail domains. Nature 1995;373:261-4.

10. Stromer MH. The cytoskeleton in skeletal, cardiac, and smooth muscle cells. Histol Histopathol 1998;13:283-91.

11. Rahilly MA, Salter DM, Fleming S. Composition and organization of cell-substratum contacts in normal and neoplastic renal epithelium. J Pathol 1991;165:163-71.

12. Storkel S, Eble JN, Adlakha K, Amin M, Blute ML, Bostwick DG, et al. Classification of renal cell carcinoma: Workgroup No.1. Union Internationale Contre le Cancer (UICC) and the American Joint Committee on Cancer (AJCC). Cancer 1997; 80:987-9.

13. Murphy WM, Beckwith JB, Farrow GM. Tumors of the kidney, bladder, and related urinary structures. Atlas of tumor pathology. 3rd ed. Washington, DC: Armed Forces Institute of Pathology; 1994. p. 92-152.

14. Mostofi FK, Davis CJ. Histological typing of kidney tumours. International histological classification of tumours. 1st ed. World Health Organization. Berlin: Springer; 1981.

15. Thoenes W, Storkel S, Rumpelt HJ. Histopathology and classification of renal cell tumors (adenoma, oncocytomas and carcinomas). The basic cytological and histopathological elements and their use for diagnosis. Path Res Pract 1986;181: 125-43.

16. Kovacs G. Molecular differential pathology of renal cell tumours. Histopathology 1993;22:1-8.

17. Flemings S. The impact of genetics on the classification of renal carcinoma. Histopathology 1993;22:89-92.

18. Van den Berg, Van der Hout AH, Oosterhuis JW, Storkel S, Dijkhuizen T, Zweers HMM, et al. Cytogenetic analysis of epithelial renal-cell tumors: relationship with a new histopathologic classification. Int J Cancer 1993;55:223-7.

19. Mostofi FK, Davis CJ. Histological typing of kidney tumours. International histological classification of tumours. 2nd ed. World Health Organization. Berlin: Springer; 1998.

20. Kovacs G, Akhtar M, Beckwith BJ, Bugert P, Cooper CS, Delahunt B, et al. The Heidelberg classification of renal cell tumours. J Pathol 1997;183:131-3.

21. Thoenes W, Storkel ST, Rumpelt HJ, Baum HP, Werner S. Chromophobe cell renal carcinoma and its variants-a report on 32 cases. J Pathol 1988;155:277-87.

22. Erlandson RA, Shek TWH, Reuter VE. Diagnostic significance of mitochondria in four types of renal epithelial neoplasms: an ultrastructural study of 60 tumors. Ultrastruct Pathol 1997;21:409-17.

23. Latham B, Dickersin CR, Oliva E. Subtypes of chromophobe cell renal carcinoma. An ultrastructural and histochemical study of 13 cases. Am J Surg Pathol 1999;23:530-5.

24. Ro JY, Ayala AG, Sella A, Samuels ML, Swanson DA. Sarcomatoid renal cell carcinoma. A clinicopathologic study of 42 cases. Cancer 1987;59:516-26.

25. Akhtar M, Tulbah A, Karder AH, Ali MA. Sarcomatoid renal cell carcinoma: the chromophobe connection. Am J Surg Pathol 1997;21:1188-95.

26. Baer SC, Ro JY, Ordonez NG, Maiese RL, Loose JH, Grignon DG, et al. Sarcomatoid collecting duct carcinoma: a clinicopathologic and immunohistochemical study of five case. Hum Pathol 1993;24:1017-22.

27. Tickoo SK, Amin MB, Zarbo RJ. Colloidal iron staining in renal epithelial neoplasms, including chromophobe renal cell carcinoma. Emphasis on technique and patterns of staining. Am J Surg Pathol 1998;22:419-24.

28. Tickoo SK, Amin MB, Linden MD, Lee MW, Zarbo RJ. Antimitochondrial antibody (113-1) in the differential diagnosis of granular renal cell tumors. Am J Surg Pathol 1997;21:92230.

29. Kuroda N, Hayashi Y, Matozaki T, Hanioka K, Gotoh A, Wang W, et al. Differential expression of SHP2, a protein-tyrosine phosphatase with SRC homology-2 domains, in various types of renal tumour. Virchows Arch 1998;433:331-9.

30. Taki A, Nakatani Y, Misugi K, Yao M, Nagashima Y. Chromophobe renal cell carcinoma: an immunohistochemical study of 21 Japanese cases. Mod Pathol 1999;12:310-7. 